\title{
Envisioning the future: Police and public health joining forces
}

\author{
Marc Krupanski, ${ }^{*}$ Melissa Jardine, ${ }^{\dagger}$ Brendan Cox, ${ }^{\ddagger}$ Tim France, $§$ Bill Stronach,\# and Nick Crofts"
}

From Minneapolis to Lagos, and from Rio de Janeiro to Nairobi, people are demanding fundamental change not only to the ways in which their communities are policed but more essentially to how complex social problems and challenges are responded to, and by whom.

The police killing of George Floyd in the United States on May 25 ignited mass calls for justice and for new approaches to addressing and promoting community safety and wellbeing. High-profile incidents of police violence and use of force have been noted in cities and countries on every continent, ushering forth new movements for police reform. These calls for change have varied in their specificity and focus but include demands for a rebalancing of investment in policing, including shifts away from punitive and militarized models of social control that have yielded an excess of police violence and incarceration. Existing models are widely recognized as reinforcing deep-rooted social, economic, and ethnic and racial inequalities. In many parts of the Global South, current models are deeply rooted in the history of colonization and the police structures, cultures, and legislation emerging from colonialism.

Meanwhile, the impact of the novel coronavirus pandemic has generated a debate on what exactly constitutes community safety and well-being, what are the best ways to encourage compliance with collective needs and concerns and who should ensure and enforce this compliance. The disparities in many countries in funding and responses between the public health and public security sectors have been stark. Many in law enforcement have also questioned the appropriateness of being tasked with enforcing quarantine measures or other public health requirements and have deplored the lack of readily available alternatives.

These debates and challenges are far from new or surprising. For years, practitioners, researchers, and advocates have articulated ways in which community safety and health are mutually reinforcing and constitutive. Likewise, they have argued for new approaches to safety and health that can build effective and appropriate partnerships between police and public health and offer alternatives to a sole focus on punitive enforcement measures. They have also argued that many complex social problems are better understood as, and should be considered as, health issues rather than criminal matters. The role of policing in addressing complex social issues, the partnership of law enforcement with public health, and the meaning and value of "public health policing" are all being currently debated, and there is much evidence that many chronic social problems require new approaches. There have been positive developments in policing-and in the police and public health partnership approach-but these are relatively few. Indeed, there are often more examples of regression to failed strategies. Polarization increases as a consequence; there is urgent need for resolution of this polarization.

We have no illusion that these deep structural and historical problems can be solved quickly. However, it will surely be a failure if, a year on from the death of George Floyd and the subsequent uprisings in cities across the world, we are still talking simply about the problems we are facing and not about actually implementing practical measures to try to resolve them. That is where this current initiative of the Global Law Enforcement and Public Health Association (GLEPHA) comes in.

Leading up to the 6th International Conference on Law Enforcement and Public Health, in March 2021, the Centre for Law Enforcement and Public Health (CLEPH), on behalf of GLEPHA, will investigate, document, showcase, and propose ways to increase accessibility to practical, alternative, and innovative approaches to current problematic issues-and will demonstrate viable alternative futures. We will be focusing on six regions globally, as we have witnessed the value of and potential for international and comparative learning and exchange. If we are to break free from entrenched structural, cultural, and historical problems that plague our communities, we must look elsewhere for lessons learned and, most importantly, for inspiration to try something new.

This is a historic moment: the opportunity to envisage a new way of achieving community safety and well-being for the whole community. The aim of this endeavour is therefore to respond to and meet this challenge in countries around the world and to take up the questions of the role of policing in democratic societies, of the best partnerships

Correspondence to: Nick Crofts, 309 George Street, Doncaster, Victoria, 3108, Australia.
E-mail: nick.crofts@unimelb.edu.au
To cite: Krupanski, M., Jardine, M., Cox, B., France, T., Stronach, B., \& Crofts, N. (2020). Envisioning the future: Police and public health joining forces. Journal of Com-
munity Safety and Well-Being, 5(4), 136-137. https://doi.org/10.35502/icswb.169
@ Author(s) 2020. Open Access. This work is distributed under the Creative Commons BY-NC-ND license. For commercial re-use, please contact sales@sgpublishing.ca. gPUBLISHING Published by SG Publishing Inc. CSAA Official publication of the Community Safety Knowledge Alliance. 
between police, public health, and government, and of how we can best meet community safety and health needs and respect the rights and dignity of all people, especially those most marginalized.

There is hunger for alternatives. Much resistance to structural changes in policing stems from a lack of imagination, acknowledgement, or knowledge of alternatives. Rather than restate problems that have been detailed and named repeatedly, this project focuses on solutions and paths forward. While not countless, examples around the world of alternative approaches to community safety and health needs do exist, and they remain little known or without sufficient profile. These range in the spectrum from cooperation between health and law enforcement to the foregrounding of actors other than law enforcement in response to community needs.

This initiative will embark on a journey to document examples of these from countries around the world, conduct a series of online activities including webinars, and launch papers and documentaries detailing these experiences at the
LEPH2021 conference in March 2021 and beyond. This is the first stage of imagining a better future.

CLEPH: https://cleph.com.au/ GLEPHA: https://gleapha.wildapricot.org/

CONFLICT OF INTEREST DISCLOSURES

This project is partly funded by the Open Society Foundations (OSF). MK is an employee of OSF.

\section{AUTHOR AFFILIATIONS}

* Public Health Program, Open Society Foundations, New York, USA; ${ }^{+}$ Melissa Jardine, Centre for Law Enforcement and Public Health; Global Law Enforcement and Public Health Association, Sydney, Australia; ‡ National Support Bureau, Law Enforcement Assisted Diversion, Albany NY, USA; \& Inis Communication, Bournemouth, UK, and Chiang Mai, Thailand; " Centre for Law Enforcement and Public Health; Global Law Enforcement and Public Health Association, Melbourne, Australia; II Centre for Law Enforcement and Public Health; Global Law Enforcement and Public Health Association; Melbourne School of Population and Global Health, Melbourne, Australia. 